\title{
Performance Analysis of Channel Assignment Scheme in Wimax
}

\author{
Dr. M. Mahbubur Rahman ${ }^{1}$, Md. Amzad Hossain ${ }^{2}$, \\ Tarek Hasan-Al-Mahmud ${ }^{3}$ and A. R. Mahmud ${ }^{4}$ \\ ${ }^{1}$ Professor, Dept. of ICE, Islamic University, Kushtia-7003, Bangladesh, \\ ${ }^{2}$ Student, Dept. of ICE, Islamic University, Kushtia-7003, Bangladesh, \\ ${ }^{3,4}$ Assist. Professor, Dept. of ICE, Islamic University, Kushtia-7003, Bangladesh,
}

\begin{abstract}
Along with information technology of flourishing, the popularization rate of wireless communication equipment is higher. However, WiMAX is the one of new broadband wireless technologies. The performance of mobile WiMAX system is highly dependent on channel assignment scheme because frequency spectrum is finite in wireless communication systems. There are two exist channel assignment scheme in WiMAX namely No Prioritized Scheme (NPS) and Reserved Channel Scheme (RCS). In this paper propose new channel assignment scheme namely Temporal Reserved Channel Scheme (TRCS) for improve performance of channel assignment scheme in WiMAX. Performance of channel assignment scheme in WiMAX depend on four probabilities such as Blocking Probability $\left(p_{b}\right)$, Handover Failure $\left(p_{h}\right)$, Forced Termination Probability $\left(p_{f t}\right)$ and Probability of Not Completed Calls $\left(p_{n c}\right)$.
\end{abstract}

Keywords- WiMAX, NPS, RCS, TRCS, Channel assignment scheme, $p_{b}, p_{h}, p_{f t}, p_{n c}$.

\section{Introduction}

WiMAX, meaning Worldwide Interoperability for Microwave Access, is a telecommunications technology aimed at providing wireless data over long distances in a variety of transmission modes, from point-to-point and point-to-multipoint links to portable and full mobile cellular type access. WiMAX, based on the wireless MAN (IEEE 802.16 and IEEE 802.16e) standard. This technology can provide broadband wireless access (BWA) up to 30 miles $(50 \mathrm{~km})$ for fixed stations, and $3-10$ miles $(5-15 \mathrm{~km})$ for mobile stations. WiMAX Forum certified systems can be expected to deliver capacity of up to 70 Mbps per channel for fixed and portable access applications[1][2][11][12].

In the channel assignment scheme, the channel is divided into reservation and dynamic channel. In the circumstance of low requirement, the reservation channel cannot utilize the resource allocated fully. However, the dynamic channel can be adjusted according to requirement of transmission to enhance the channel utilization. For this reason, a part of the channel is reserved to offer the users who raise the requirement in the first time. Then the dynamic channel allocation is used to share the remnant of channel and to utilize the resource effectively[13].

The rest of the paper is organized as follows: Section II, gives a brief overview of previous channel assignment scheme in WiMAX. Section III, describes the proposed channel assignment scheme in WiMAX. Section IV, the simulation result is presented in this section. Section V, conclusions of the paper. Section VI, acknowledgment of the paper.

\section{Previous Channel Assignment Scheme In WiMAX}

In this section, channel assignment in WiMAX is introduced which includes No Priority Scheme (NPS) and Reserved Channel Scheme (RCS).

\section{A. Channel Assignment in WiMAX}

As WiMAX has two types fixed and mobile, so channel assignment strategies are different for both. Multiple access technique used for sub channelization in mobile WiMAX is OFDMA.

In mobile WiMAX (IEEE 802.16e) we have both, fixed and mobile users. So here mobility conditions come into account and we cannot ignore the inter-cell movement of users. So here all the channel assignment strategies (Fixed Channel Assignment (FCA), Dynamic Channel Assignment (DCA), Hybrid Channel Assignment (HCA) and Borrowing Channel Assignment (BCA) in[4]) come into account. In mobile WiMAX we use both for better performance of the cellular network. Now in mobile WiMAX we have both types of users, fixed and mobile, so for fixed users (broadband) we need to provide fixed channels (permanent channels). It is better to use both FCA and DCA schemes together (HCA) in[4] High traffic load in a cell results in increasing blocking probability, forced termination and Handover failure etc. For this purpose to reduce the probabilities of blocking $\left(p_{b}\right)$, handover failure $\left(p_{h}\right)$, forced termination $\left(p_{f t}\right)$ and of not completed calls $\left(\left(p_{n c}\right)\right.$, 
have two channel assignment schemes, No Priority Scheme (NPS) and Reserved Channel Scheme (RCS), in WiMAX Cells. We need to understand the concept of NPS and RCS deeply[4] [10].

\section{B. No Priority Scheme (NPS)}

NPS is a non-prioritized channel assignment scheme. Non-prioritized means that all calls in a cell have the same priority to be allocated a channel. In this scheme there are no reserved channels included, so there is no permanent channel assignment also. Any user who makes a call attempt 1st will be allocated a channel. So it is basically a first come first serve scheme. No permanent channel assignment is supported by NPS. So we consider that in NPS, fixed WiMAX broadband office users, where disconnection is intolerable, may also face blocking probability as well if placed in a cell with high traffic load. So we can say NPS scheme is better for implementation in cells where we do not have high traffic intensity, so that blocking probability may never occur. In high traffic intensity it can perform better only with DCA[4].

\section{Reserved Channel Scheme (RCS)}

This is a prioritized channel assignment scheme. In this scheme priority is set for the channel assignment for all types of functions performed in the cell. These functions include; call attempts, handovers and permanent channel assignment. Highest priority is set for permanent channel assignment, then for handovers and then for call attempts. This priority is set by reserving channels for permanent assignment and handovers. Reserved channels are never used for new calls in the cell [8]. Similarly reserved channels used for permanent allocation are never used for handover and vice versa. In this case the permanent channels for permanent users and reserved channels for handovers can be implemented using FCA and remaining channels using DCA[4][10].

\section{Definition of four probabilities}

The analytical method is to drive the Blocking Probability $\left(p_{b}\right)$, Handover Failure $\left(p_{h}\right)$, Forced Termination Probability $\left(p_{f t}\right)$ and Probability of Not Completed Calls $\left(p_{n c}\right)$ in a WiMAX cell. These probabilities are defined as:

Blocking Probability $\left(p_{b}\right)$ : The probability that all channels in the cell are busy and there is no channel available in the cell to entertain a new user is called $p_{b}$. In such a case user will be rejected to make a new connection. This is the case when user receives network busy message.

Handover Failure Probability $\left(p_{h}\right)$ : The probability that a new user, during an ongoing connection, enters the cell and its call is dropped due to all channels busy condition is called Ph. In other words new call arriving in the cell is dropped due to unavailability of a channel in that cell (handover failure).

Forced Termination Probability $\left(p_{f t}\right)$ : This is the probability that a mobile job in service, previously accepted by the system, gets terminated due to handover failure, after a successful handover to the neighboring cell.

Probability of Not Completed Calls $\left(p_{n c}\right)$ : This is the probability of all the calls that were not completed because of any one of the three scenarios i.e. call blocking, handover failure, forced termination due to handover failure. [4]

\section{The Concept Of Temporal Reserved Channel Scheme (Tres)}

This section briefly described problems of the existing two channel assignment scheme; propose new channel assignment scheme and described our approach to solve the problems.

\section{A. Problem of No Priority Channel Scheme (NPS)}

It is used then Blocking Probability $\left(p_{b}\right)$ and Probability of Not Completed Calls $\left(p_{n c}\right)$ are low, but Handover Failure Probability $\left(p_{h}\right)$ and Forced Termination Probability $\left(p_{f t}\right)$ are high. Drawback here is that permanent users will face blocking as it has same priority for channel assignment for all kinds of jobs in the cell.

\section{B. Problem of Reserved Channel Scheme (RCS)}

It is used then Handover Failure Probability $\left(p_{h}\right)$ and Forced Termination Probability $\left(p_{f t}\right)$ are low, but Blocking Probability $\left(p_{b}\right)$ and Probability of Not Completed Calls $\left(p_{n c}\right)$ are high. In RCS, reduce Handover Failure Probability $\left(p_{h}\right)$ because here take reserved channel for only handover, but increase call Blocking Probability $\left(p_{b}\right)$ because cell site can not used reserved channels for call attempt and also cell site can not used reserved channel for call attempt when reserved channels are free. This is main problem of RCS.

\section{Our Approach}

We propose new channel assignment scheme to solve the problems of existing two channel assignment scheme. The name of new channel assignment scheme is "Temporal Reserved Channel Scheme (TRCS). 


\section{Temporal Reserved Channel Scheme (TRCS)}

This is a prioritized channel assignment scheme. In this scheme priority is set for the channel assignment for all types of functions performed in the cell. These functions include; call attempts, handovers and permanent channel allocation. Highest priority is set for permanent channel assignment, then for handovers and then for call attempts. This priority is set by reserving channels for permanent assignment, but the priority of handover is set by temporal reserving channels. The temporal reserved channel means, this channel can be used for new call attempt, when not need handover of cell site, but when need handover and call attempt at the same time and not free call attempt channel, then temporal reserved channel used for handover purpose not call attempt purpose. If we have $\mathrm{N}$ channels in the network, then out of $\mathrm{N}$ channels $\mathrm{S}$ channels are reserved for permanent assignment and $\mathrm{K}$ channels are temporal reserved for handover. Now remaining available channels are assigned to new calls. Reserved channels are use for permanent connection but never used for new calls in the cell.

In this case we said that reserved channels for permanent connection can be implemented using FCA, temporal reserved channels for handover can be implemented by using BCA and remaining channels using DCA.

\section{E. Parameters description:}

For parameters it is assumed here that new job attempts (job can be a call attempt or a wireless broadband connection) and handover arrivals in the cell follow Poisson distribution. Channel occupancy time is distributed exponentially (channel occupancy time is the time for which channel is occupied for a job or handover process). Here in the cell, Job Arrival Intensity is represented by $\lambda o$, Handover job arrival intensity is represented by $\lambda_{h i}$, Handover Call Departure Intensity is represented by $\lambda_{h 0}$ and Permanent Job Arrival Intensity is represented by $\lambda_{p}$. Permanent job arrival intensity is kept constant because number of permanent jobs in the cell will always be same as they are fixed. Mobile user arrival intensity and handover arrival intensity may change according to the traffic conditions in the cell. Service intensity for a job until it leaves the cell (handover involved) is $\mu$ and for the job until it is completes within the cell (no handover) is [4]. In [10] it is considered that if total number of servers is $j$, then total probability is given by $p_{j}$. In WiMAX we have an additional parameter i.e. Permanent Job Arrival Intensity, represented by $\lambda_{p}$. This parameter will have no effect on NPS, so NPS results for WiMAX will be same as for PCS.

\section{F. Analytical Method for TRCS in WiMAX}

In TRCS, scenario for WiMAX is a bit different from PCS and RCS. In PCS we had reserve channels for handover purpose and remaining were used for mobile calls, as presented in [10]. In RCS we had reserved channels for permanent connection and handover purpose and remaining were used for mobile calls. Here in WiMAX scenario for TRCS we assume that we have total $s$ channels out of which ch channels are temporal reserved for handover purpose and $k$ channels are for permanent assignment to the WiMAX fixed broadband users. The channels for remaining jobs in the cell are given by:

$$
n=s-k
$$

If we do not have any permanent channels in the cell then it will be [11]

$$
n=s
$$

The arrival intensity for $n$ channels in the cell for TRCS is given by adding handover arrival intensity, job arrival intensity and permanent job arrival intensity i.e. $\lambda=\lambda_{0}+\lambda_{h i}+\lambda_{p}$. Arrival intensity in the cell for ch channels is given by only $\lambda_{h i}$ and arrival intensity for permanent channels is given by $\lambda p$. Total number of states here is also defined by Markov process i.e. $s+1$ states. State diagram for TRCS is shown in Figure 1.1. Here we have a big advantage that if all the $n$ channels are busy and new call arrive and temporal reserved channels are not use for handover purpose then temporal reserved channels can be used for established call connection in the cell, in this way reduced call Blocking Probability $\left(p_{b}\right)$ than RCS and reduced Handover Failure Probability $\left(p_{h}\right)$. Figure 1.1 is modified for WiMAX environment form the original one for RCS in[4] [10]. 


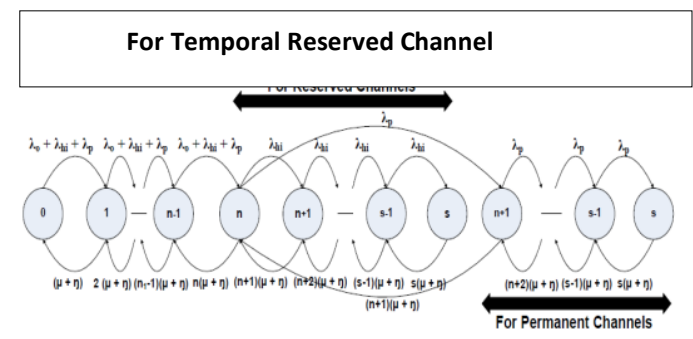

Figure 1.1: Diagram of TRCS.

From state diagram in Figure 1.1 we see that both arrival intensities for reserved and permanent channels move till the last state $s$ and both are independent of each other. To write the total probability in terms of Po we have three probabilities for $0 \leq j<n$, and for $n \leq j<k$. These are given by:

$$
\begin{gathered}
p_{j}=\frac{\left(\frac{\lambda_{o}+\lambda_{h i}+\lambda_{p}}{\mu+\eta}\right)^{j}}{j !} p_{0} \text { for } 0 \leq j<n \\
\frac{\left(\lambda_{p}\right)^{j-n}\left(\lambda_{o}+\lambda_{h i}+\lambda_{p} \lambda\right)^{n}}{j !(\mu+\eta)^{j}} p_{0} \text { for } n \leq j<s \quad \begin{array}{c}
\text { (1.3) } \\
p_{0}=
\end{array} \\
\sum_{j=0}^{n} \frac{\left(\frac{\lambda_{o}+\lambda_{h i}+\lambda_{p}}{\mu+\eta}\right)^{j}}{j !}+\sum_{j=n+1}^{s} \frac{\left(\lambda_{p}\right)^{j-n}\left(\lambda_{o}+\lambda_{h i}+\lambda_{p} \lambda\right)^{n}}{j !(\mu+\eta)^{j}}
\end{gathered}
$$$$
p_{j}=
$$

The equation of blocking probability for TRCS is given by:

$$
p_{b}=\sum_{j=n}^{s} p_{j}
$$

Where $\mathrm{n}$ is given by equation (1.1) and (1.2)depending on the presence of permanent channel in the cell. In equation (1.6) $n$ are the remaining channels left for mobile users after subtracting permanent channels. So $p_{b}$ will be sum of all the probabilities from $n$ to $s$ ( $s$ is total number of channels). So probability of handover failure for TRCS for WiMAX is given by:

$$
p_{h=} p_{s}
$$

Equation for $p_{n c}$ and $p_{f c}$ for TRCS:

The equations for $p_{n c}$ and $p_{f c}$ are taken same as presented in [9] but they depend on the above equations derived for WiMAX. So the results produced using these equations will be according to WiMAX environment. In our simulation work we have considered traffic conditions for the WiMAX cell to be uniform. So for uniform traffic conditions, parameters taken from [11] for $p_{f c}$ and $p_{n c}$ are as follows:

If a user moves to a neighboring cell, than the handover departure rate is given by:

$$
\lambda_{h 0}=\frac{\eta\left(1-p_{b}\right) \lambda_{0}}{\mu+\eta-\eta\left(1-p_{h}\right)}
$$

Probability that a new job originated in the cell will be accommodated is:

$$
\mathrm{S}=\frac{\left(1-p_{b}\right)}{\left(1-p_{b} T\right)}
$$

Where $P_{b} T=P_{b} . P_{b} T$ is the ratio of blocking probability for all cells to the total number of cells in the system. The probability that a handover is made to a neighboring cell is given by:

$$
a=\frac{\eta}{\mu+\eta}\left(1-p_{h}\right)
$$

Probability that a currently ongoing job is denied a handover is given by: 


$$
b=\frac{\eta}{\mu+\eta}\left(p_{h}\right)
$$

Probability that a job in service faces forced termination after successful Handovers is:

$$
\mathrm{E}=\frac{\eta^{p_{h}}}{\mu+\eta^{p_{h}}}
$$

Now after describing the parameters, $p_{n c}$ and $p_{f t}$ in the cell are given in [9]

$$
\begin{aligned}
& p_{n c}=1-\frac{1-p_{b}}{1+\frac{\eta^{p} h}{\mu}} \\
& p_{f c}=\mathrm{S} \times \mathrm{E}
\end{aligned}
$$

Equations (3.21) and (3.22) are same for NPS, RCS and TRCS.

\section{Simulation Result}

\section{A. Simulation Results in Three Channel Assignment Scheme}

For simulation, we have taken one assignment scheme for 70 busy channels in a WiMAX cell for NPS, RCS and TRCS.

Channel conditions used in MATLAB:

Channel Assignment Scheme [1] for $k=10 \& C h=15$

In this scenario we have considered permanent channels $k=10$ and temporal reserved channels (reserved for RCS) for handovers $c h=15$. This shows that for TRCS with permanent channels according to equation (1.1) we have $n=60$ channels and for TRCS without permanent channels according to equation (1.2) we have $n=70$ channels available for mobile jobs in the cell. For NPS we have all 70 channels available for the jobs arrival in the cell, whether they are mobile or fixed. For RCS with no permanent channel we have $\mathrm{n}=55$ and for RCS with permanent channels we have $n=45$ channels available for mobile jobs in the cell.

\section{B. Comparison of Blocking Probability $\left(p_{b}\right)$ :}

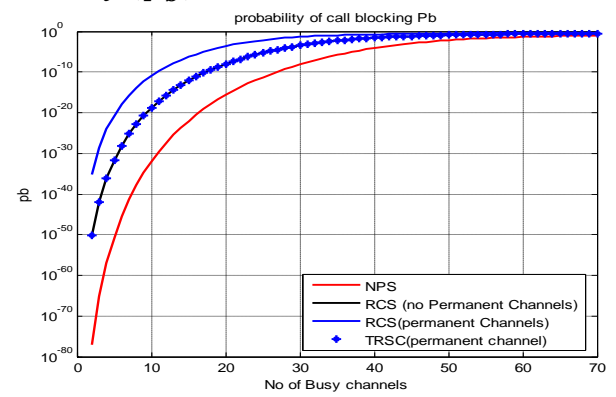

Figure 1.1: Simulation result for $p_{b}$ with $\mathrm{k}=10$ and $\mathrm{ch}=15$

Simulation result in Figure 1.1 shown the curves of Blocking Probability $\left(p_{b}\right)$ for NPS, RCS and TRCS according to the channel assignment scheme 1 .

\section{Comparison of Handover Failure Probability $\left(p_{h}\right)$ :}

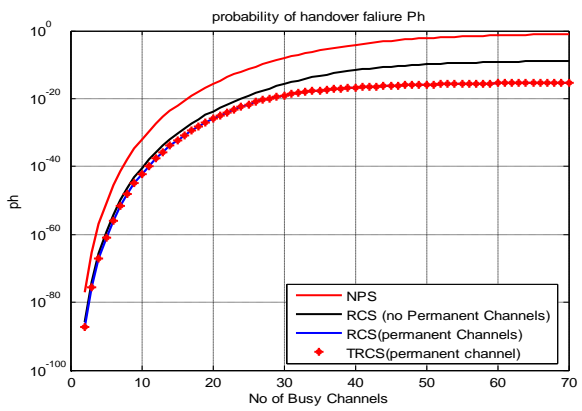

Figure1.2: Simulation result for $\mathrm{Ph}$ with $\mathrm{k}=10 \mathrm{and} \mathrm{ch}=15$.

Simulation result in Figure 1.1 shown the curves of Handover

Failure Probability $\left(p_{h}\right)$ for NPS, RCS and TRCS according to the channel assignment scheme 1. 


\section{Comparison of Forced Termination Probability $\left(\boldsymbol{p}_{f t}\right)$ :}

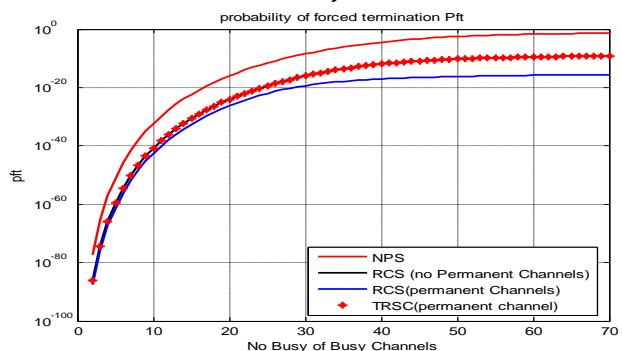

Figure 1.3: Simulation result for $p_{f t}$ with $\mathrm{k}=10$ and $\mathrm{ch}=15$.

Simulation result in Figure 1.1 shown the curves of Forced Termination Probability $\left(p_{f c}\right)$ for NPS, RCS and TRCS according to the channel assignment scheme 1.

\section{E. Comparison Probability of Not Completed calls $\left(\boldsymbol{p}_{n c}\right)$ :}

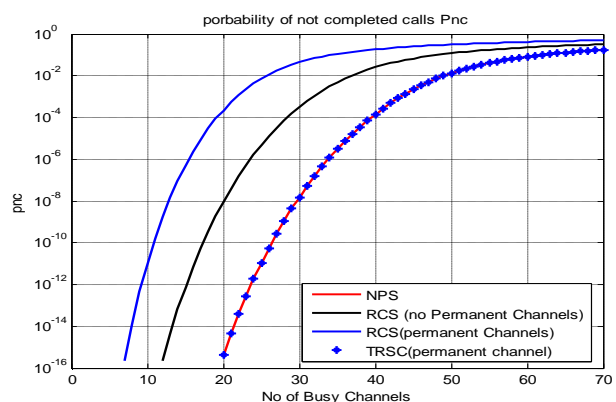

Figure 1.4: Simulation result for $p_{n c}$ with $\mathrm{k}=10$ and $\mathrm{ch}=15$

Simulation result in Figure 1.1 shown the curves of Probability of Not Completed calls $\left(p_{n c}\right)$ for NPS, RCS and TRCS according to the channel assignment scheme 1.

From Figures (1.1,1.2, 1.3 and 1.4) we observed that the simulation results of TRCS with permanent channels is : $p_{b}$ and $p_{n c}$ are low; $p_{h}$ and $p_{f t}$ are median not high.

So we can say TRCS scheme is better for implementation in WiMAX cell where some time or some hours of day increase handover process, but remaining time or hours of day decrease handover process but increase call attempts process. In this way increase the performance of channel assignment scheme in WiMAX.

\section{v. CONCLUSION}

Our conclusions are based on the probability results obtained for Probability of Not Completed Call $p_{n c}$, for NPS, RCS and TRCS because it depends on the other probabilities obtained $\left(p_{b}, p_{h}\right.$ and $\left.p_{f c}\right)$. From the simulation results Probability of Not Completed Calls $\left(p_{n c}\right)$ are high. We conclude that RCS should be used in a cell where permanent channels are required to be assigned and where need more handover in all time.

From the simulation results, for the NPS then Blocking Probability $\left(p_{b}\right)$ and Probability of Not Completed Calls $\left(p_{n c}\right)$ are low, but Handover Failure Probability $\left(p_{h}\right)$ and Forced Termination Probability $\left(p_{f c}\right)$ are high. Drawback here is that permanent users will also face blocking. We concluded that NPS can yield good results if it is used in a WiMAX cell environment only if there is no permanent channel assignment required in that cell.

From simulation we observed that the simulation results of TRCS with permanent channels is: $p_{h}$ and $p_{n c}$ are low ; $p_{b}$ and $p_{f c}$ are median not high. We concluded that TRCS scheme is better for implementation in WiMAX cell where some time or some hours of day increase handover process, but remaining time or hours of day decrease handover process but increase call attempts process. In this way increased the performance of channel assignment scheme in WiMAX.

\section{ACKNOWLEDGMENT}

This work was supported by Department of Information \& Communication Engineering , Islamic University, Bangladesh. 


\section{References}

[1] Frank Ohrtman, "WiMAX Handbook-Building 802-16 wireless network"

[2] http://www.intel.com/netcomms/technologies/WiMAX

[3] Ajay R. Mishra, "Cellular Network Planning and Optimisation 2G/2.5G/3G...Evolution to 4G"

[4] Muhammad Rehan Usman ,Johar Iqbal Fahad Razzaq This thesis is presented as part of Degree of Master of Science in Electrical Engineering Blekinge Institute of Technology November 2009.

[5] WiLAN WiMAX Networks,[online].Available:http://www.conniq.com/WiMAX/handoff.html [Accessed Nov.15.2009

[6] Noman Shabbir, Hasnain Kashif Radio Resource Management in WiMAX: RF Planning in WiMAX, Chapter 3, LAP Lambert cademic Publishing.

[7] Syed Ahson and Mohammad Ilyas, "WiMAX Technologies Performance Analysis, and QoS".

[8] IEEE standard for local and metropolitan area networks part 16: Air interface for fixed broadband wireless access systems. IEEE sTD 802.16TM-2004, Tech. Rep, 2004.

[9] Chapter 08: Channel Allocation, [Online]. Available: www.cs.purdue.edu/homes/bb/cs690b/Chapt-08.ppt [Accessed] Nov 16.2009].

[10] L. O. Guerrero, A. H. Aghvami, “A Prioritized Handoff Dynamic Channel Allocation Strategy for PCS,” IEEE Transactions on Vehicular Technology, Volume 48, No. 4.

[11] B. Han, W. Jia and L. Lin, "Performance evaluation of scheduling in IEEE 802.16 based wireless mesh networks," Computer Communications, 30(4), 2007, pp. 782-792.

[12] K. Vinay, N. Sreenivasulu, D. Jayaram and D. Das, "Performance evaluation of end-to-end delay by hybrid scheduling algorithm forQoS in IEEE 802.16 network," Proceedings of the IFIP International Conference on Wireless and Optical Communications etworks,006, pp. 1-5.

[13] S.C. Wang, K.Q. Yan and C.H. Wang, "A Channel Allocation based WiMAX Topology”.

\section{AUTHORS BIOGRAPHY}
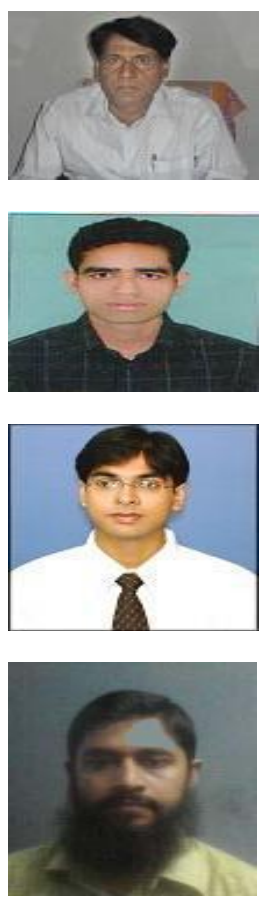

Dr. M. Mahbubur Rahman received his B. Sc. and M. Sc from Rajshahi University in Physics. He is currently working as Professor in Information \& Communication Engineering department, Islamic University, Kushtia-7003, Bangladesh.

Md. Amzad Hossain received B.Sc Degree in 2010 from Dept. of Information \& Communication Engineering, Islamic University, Kushtia-7003, Bangladesh.

Tarek Hasan-Al-Mahmud received his B.Sc. and M. Sc. in Information \& Communication Engineering from Islamic University, Kushtia-7003, Bangladesh He was Lecturer in Computer Science \& Telecommunication Engineering, Noakhali Science \& Technology University. He is currently working as Assistant Professor in ICE department., Islamic University, Kushtia-7003, Bangladesh.

Ashek Raihan Mahmud received his B. Sc. from Rajshahi University of Engg. and Technology, Bangladesh and M.Sc. from Royal Melbourne Institute of Technology, Australia. He is currently working Assistant Professor in Information \& Communication Engineering department, Islamic University, Kushtia-7003, Bangladesh. 